\title{
Vitamin D receptor $C d x$-2-dependent response of central obesity to vitamin D intake in the subjects with type 2 diabetes: a randomised clinical trial
}

\author{
Sakineh Shab-Bidar ${ }^{1}$, Tirang R. Neyestani ${ }^{2}$ and Abolghassem Djazayery ${ }^{1}$ \\ ${ }^{1}$ Department of Community Nutrition, School of Nutritional Sciences and Dietetics, Tebran University of Medical Sciences \\ (TUMS), Tebran, Iran \\ ${ }^{2}$ Laboratory of Nutrition Research, National Nutrition and Food Technology Research Institute (NNFTRI) and Faculty of \\ Nutrition and Food Science; Shabid Beheshti University of Medical Sciences (SBUM), 1981619573 Tehran, Iran
}

(Submitted 18 February 2015 - Final revision received 7 June 2015 - Accepted 7 July 2015 - First published online 8 September 2015)

\section{Abstract}

This study aimed to investigate the effects of daily intake of vitamin D-fortified yogurt drink (doogh) on central obesity indicators in subjects with type 2 diabetes (T2D) and the possible modulation of this effect by vitamin D receptor (VDR) $C d x$ - 2 genotypes. A total of sixty T2D subjects were randomly allocated to two groups to receive either plain doogh (PD; $n$ 29, containing $170 \mathrm{mg}$ Ca and no vitamin D/250 ml) or vitamin $\mathrm{D}_{3}$-fortified doogh (FD; $n$ 31, containing $170 \mathrm{mg} \mathrm{Ca}$ and $12.5 \mu \mathrm{g} / 250 \mathrm{ml}$ ) twice a day for 12 weeks. 25-hydroxyvitamin D (25(OH)D), glycaemic as well as adiposity indicators were evaluated before and after the intervention. VDR-Cdx-2 genotypes in extended number of T2D subjects in the FD group ( $n$ 60) were determined as AA, GA and GG. After 12 weeks, in FD compared with PD, serum 25(OH)D increased $(+35.4 v .-4.8 \mathrm{nmol} / 1 ; P<0.001)$ and mean changes of waist circumference (WC; $-1.3 v+1.6 \mathrm{~cm} ; P=0.02)$, body fat mass (FM; $-1.9 v .+0.60 \%$; $P=0.008)$, truncal fat (TF; $-1 \cdot 1 v \cdot 0 \cdot 13 \% ; P=0.003)$ and visceral adipose tissue $(-0.80 v .+0.37$ AU; $P<0 \cdot 001)$ decreased significantly. Circulating 25(OH)D was raised only in the AA group ( $34.8 \mathrm{nmo} / 1$ in AA group $v$. $-6.4 \mathrm{nmol} / \mathrm{l}$ in AG and $-1.6 \mathrm{nmol} / 1$ in GG groups; $P<0.001)$, which was accompanied by a significant decrease in changes of WC $(P=0.004)$, FM\% $(P=0.01)$ and TF\% $(P<0.001)$ in the AA genotype. Daily intake of vitamin D-FD for 12 weeks improved the central obesity indices in T2D subjects, and the improvement was more pronounced in the carriers of the AA genotype of VDR- $C d x-2$.

Key words: Vitamin D: Adiposity: Fat mass: Visceral fat: Type 2 diabetes: Vitamin D receptor: Vitamin D receptor genotype

Obesity, the accumulation of excessive amount of body fat, is the most common disorder globally, including low- and middleincome countries like $\operatorname{Iran}^{(1)}$ and an important cause of morbidity and mortality, which can create enormous socioeconomic and public health burdens for poorer nations ${ }^{(2)}$. The distribution of body fat is of great importance as truncal or central obesity is mostly associated with many pathologies, including CVD, hypertension and diabetes. The pathogenesis of central obesity is complex, comprising both genetic and environmental factors. It is estimated that $40-70 \%$ of the variation in BMI and $37-81 \%$ in waist circumference (WC) is heritable, although cultural and social factors may explain at least $30 \%$ of the variations ${ }^{(3,4)}$. Current literature supports an inverse relationship between 25-hydroxyvitamin D (25(OH)D) and components of the metabolic syndrome, including high blood glucose concentration, insulin resistance, dyslipidaemia, elevated blood pressure and abdominal obesity ${ }^{(2)}$. Obesity is associated with a lower concentration of circulating $25(\mathrm{OH}) \mathrm{D}$, and poor vitamin $\mathrm{D}$ status is independently associated with increased BMI and fat mass (FM) ${ }^{(5-9)}$. BMI, although commonly used as an indicator of adiposity, has a limitation of undifferentiating FM from fat-free mass. Furthermore, the ethnicity may have an effect on the relationship between BMI and body FM. For example, Asians are reported to exhibit a higher proportion of body fat for a given BMI than do Caucasians ${ }^{(10)}$. On one hand, vitamin D has lower bioavailability in obese patients due to sequestration of vitamin $\mathrm{D}$ in adipose tissue, and, on the other hand, vitamin D may play a causal role in obesity by modulating homoeostasis of intracellular $\mathrm{Ca}$ in which a higher intracellular Ca triggers lipogenesis and suppresses lipolysis ${ }^{(11)}$. Recently, a meta-analysis of randomised clinical trials (RCT) showed beneficial effects of vitamin D supplementation on body weight and $\mathrm{FM}^{(12)}$. Nevertheless, prospective studies examining the effects of $\mathrm{Ca}$ and vitamin $\mathrm{D}$ alone or in combination on body weight and/or abdominal fat have been inconclusive $^{(8,13)}$.

Both $1,25(\mathrm{OH}) 2 \mathrm{D}$ and vitamin $\mathrm{D}$ receptor (VDR) are important contributors in adipocyte differentiation ${ }^{(14,15)}$. It has

Abbreviations: 25(OH)D; 25-hydroxyvitamin D; FD; fortified doogh; FM; fat mass; HbA1c; glycated Hb; PD; plain doogh; QUICKI; Quantitative Insulin Check Index; TF; trunk fat; T2D; type 2 diabetes; VAT; visceral adipose tissue; VDR; vitamin D receptor; WC; waist circumference.

*Corresponding author: T. R. Neyestani, email neytr@yahoo.com 
been demonstrated that VDR mRNA concentration affects adipogenesis, that is, it may have inducing or hindering effect $^{(16)}$. Moreover, VDR is able to bind to several genes to influence their expression. Among VDR SNP, $C d x-2$ is functional and resides in the binding site of transcription factor $C d x$-2, upstream of exon 1 . Functional analyses showed that the A to $\mathrm{G}$ base substitution eliminates the $C d x-2$ binding site and reduces transcriptional activity of VDR to $70 \%$ of the A allele ${ }^{(17)}$. It was suggested that $C d x-2$ is associated with decreased risk of fracture with A allele via enhancing VDR expression in the intestine, increasing $\mathrm{Ca}$ transport protein transcription leading to increased $\mathrm{Ca}$ absorption and increased bone mineral density. On the other hand, epidemiologic data show an inverse association between Ca consumption and body fat (particularly in women) and the risk of becoming obese ${ }^{(18)}$. A few studies have examined the association of various VDR genetic variants with adiposity. Recently, Ochs-Balcom et al. ${ }^{(19)}$ showed a borderline significant association between $C d x$-2 polymorphism and adiposity phenotype. Rosenblum et $a l^{(20)}$ noted that $\mathrm{Ca}$ and/or vitamin D supplementation contributes to a beneficial reduction of visceral adiposity.

Given the potential risk of vitamin D deficiency for major non-skeletal diseases and conditions such as metabolic syndrome, type 2 diabetes (T2D), CVD and obesity, and the role of VDR genetic variants in adiposity, we conducted the current study to investigate the effects of vitamin $\mathrm{D}$ intake through fortified Persian yogurt drink ( $\operatorname{doog} h)$ for 12 weeks on markers of central obesity and whether $C d x-2$ SNP could modify the possible effects of vitamin $\mathrm{D}$ on central obesity indicators.

\section{Methods \\ Study design}

This was a 12-week single-blind RCT and a part of a larger trial on evaluation of efficacy of vitamin D-fortified $\operatorname{doog} h$ (FD) on diabetes outcomes in T2D patients. The protocol of this trial has been published in detail previously ${ }^{(21)}$. The RCT was conducted during the period of mid-October 2010 to late March 2011 collaboratively by National Nutrition and Food Technology Research Institute (NNFTRI) and Tehran University of Medical Sciences (TUMS) in Tehran, the capital of Iran. Full information on the study design and objectives had been given to all participants before they gave a signed informed consent. The study protocol was approved scientifically and ethically by both NNFTRI and TUMS. The trial registration number at ClinicalTrials.gov is NCT01236846.

\section{Subjects, inclusion/exclusion criteria}

Data from the subjects of our previous trial ${ }^{(22)}$ in whom visceral adiposity had been assessed were used for the current study. Participants were recruited from the Iranian Diabetes Society and Gabric Diabetes Society members. Volunteers were invited to attend the Laboratory of Nutrition Research at NNFTRI while they were fasting for $12-14 \mathrm{~h}$.

The inclusion criteria were: (a) fasting blood glucose $>7 \mathrm{mmol} / \mathrm{l}$, (b) aged 30-60 years old, (c) willingness to participate and (d) no intake of vitamin, dietary, herbal or $n-3$ supplements since at least 3 months prior to the intervention. Exclusion criteria were: (a) history of CVD, gastrointestinal, renal and other endocrinological diseases, (b) pregnancy or lactation, (c) receiving insulin and (d) treatment for weight reduction.

\section{Study protocol, randomisation and intervention}

A run-in period was considered for 2 weeks during which the subjects were instructed to have a weight maintenance diet according to the American Diabetes Association guidelines ${ }^{(23)}$, including two servings of low-fat dairy products (milk and yogurt) and two to three servings of fruits, and two to three servings' effects of daily intake of two servings of vitamin $\mathrm{D}_{3}$-FD as compared with plain doogh (PD) on obesity indices were evaluated in T2D patients.

To do the RCT, participants were selected from the original database ${ }^{(24)}$ in which the random allocation of participants was done. Then those participants whose visceral adipose tissue (VAT) data were available were enrolled. As fully described earlier $^{(24)}$, participants were assigned to one of the treatment groups of either FD (containing $170 \mathrm{mg} \mathrm{Ca}$ and $12.5 \mu \mathrm{g}$ vitamin $\mathrm{D}_{3} / 250 \mathrm{ml} ; n_{1} 31$ ) or PD (containing $170 \mathrm{mg} \mathrm{Ca}$ and no vitamin $\left.\mathrm{D} / 250 \mathrm{ml} ; n_{2} 29\right)$, using computer-generated random numbers. The team members involved in the intervention had to be aware of the group assignment; thus, the study was only partly blinded. Laboratory staff did not know the patients' group assignments. Participants were instructed to consume a bottle of yogurt drink with both lunch and dinner, that is, $500 \mathrm{ml} / \mathrm{d}$ equalling $25 \mu \mathrm{g}$ (1000 IU) vitamin $\mathrm{D}_{3} / \mathrm{d}$ in the FD group. The intervention period was 12 weeks. In the second part (nutrigenetic study), number of patients in the FD group was extended ( $n$ 60) to investigate the possible role of VDR SNP, $C d x-2$, in the response of obesity indicators to vitamin D intake.

\section{Compliance and quality control}

Every 2 weeks, all subjects were visited to evaluate their compliance and to provide a new package of doogh. Yogurt drinks were identical in colour, size, taste and packaging. Therefore, participants were not aware of their group, nor were all the interviewers and laboratory staff. Compliance was evaluated by checking the consumption tables, counting the empty bottles and by direct enquiry both on biweekly visits and weekly follow-up phone calls. The composition (including vitamin D) of dooghs was determined immediately after production, in the middle and at the end of the storage period, to ensure the stability of the components. The measurements were taken at Maad Laboratory of Foods, Drinks and Cosmetics, accredited by the Food and Drug Organization of the Iran Ministry of Health.

\section{Measurements}

\section{Assessment of dietary intakes and other variables}

We assessed dietary intakes by employing three $24 \mathrm{~h}$ recalls questionnaire (including a weekend day) in the beginning of study, which was repeated in the end of the intervention period, as described earlier ${ }^{(24)}$. To translate dietary intake data to the 
actual amounts of energy and nutrients, food composition tables of US Department of Agriculture with some modifications for Iranian foods were used. Information on demographic, medical history, physical activity, duration of direct sun exposure and smoking habits are gathered using questionnaires and face-to-face interview.

\section{Anthropometrics}

Weight was measured with light clothing and without shoes using a digital scale (Seca 808 ) to the nearest of $0.1 \mathrm{~kg}$. Height was measured without shoes using a stadiometer (Seca) to the nearest of $0.1 \mathrm{~cm}$. Circumferences of the waist and hip were evaluated by a measuring tape to the nearest of $0 \cdot 1 \mathrm{~cm}$. BMI was calculated using the equation BMI $=$ weight $(\mathrm{kg}) /$ height $^{2}\left(\mathrm{~m}^{2}\right)$.

\section{Assessment of percentage of body fat and visceral fat mass}

To evaluate the percentage of body FM, bioelectrical impedance analysis (Quadscan 4000 system; Bodystat) was employed. The percentage of trunk fat (TF) and the degree of VAT were evaluated by the Tanita AB-140 ViScan (Tanita Corporation). All participants were requested to abstain from any food or liquid intake and from any intensive exercise for at least $4 \mathrm{~h}$ before evaluation. They were also instructed not to wear any metallic object for the tests. The assessments were conducted in an ambient room temperature, while patients were laid on a non-conductive surface. Participants were in a supine position, without a pillow, while their arms were laid across the chest. According to the manufacturer's instructions, the ViScan was positioned perpendicular to the participant's body at the umbilical level. The multi-frequency electrode device was positioned on the abdomen in direct contact with the skin. The evaluations were made in duplicate.

\section{Laboratory investigations}

Blood samples were collected after $12 \mathrm{~h}$ of overnight fasting and were divided in two tubes either with or without the anticoagulant, EDTA. The anticoagulated tube was used to extract genomic DNA, whereas the sera recovered from clot samples were used for biochemical analyses. Glycaemic status and circulating 25(OH)D were determined as previously described ${ }^{(25)}$. In this study, vitamin $D$ status was defined based on serum concentrations of $25(\mathrm{OH}) \mathrm{D}$ as: sufficiency $\geq 50 \mathrm{nmol} / \mathrm{l}$, $27.5 \mathrm{nmol} / 1 \leq$ insufficiency $<50 \mathrm{nmol} / \mathrm{l}$ and deficiency $<27.5$ $\mathrm{nmol} / \mathrm{l}^{(26)}$. According to the Institute of Medicine, these cutoffs were set based on the fact that the vitamin $D$ requirements of at least $97.5 \%$ of the population can be met with circulating 25 $(\mathrm{OH}) \mathrm{D}$ concentrations of $50 \mathrm{nmol} / \mathrm{l}^{(27)}$. Fasting serum glucose (FSG) was determined using enzymatic method by using commercial kits (Pars Azmoon) and an auto-analyzer system (Selectra E; Vitalab). Glycated Hb (HbA1c) was determined using colorimetric method after an initial chromatographic separation (BioSystems). Fasting serum insulin was assayed by immuno-radiometric assay (Biosource) and a gamma-counter system (Gamma I; Genesys). The intra- and inter-assay variations for all tests were $<7$ and $9 \%$, respectively. Insulin sensitivity was evaluated by Quantitative Insulin Check
Index (QUICKI) calculated as ${ }^{(28)}$ : QUICKI index: 1/(log (insulin) $(\mu \mathrm{U} / \mathrm{ml})+\log ($ glucose $)(\mathrm{mg} / \mathrm{dl}))$.

\section{Genotyping}

DNA was extracted from anticoagulated blood samples using Genet Bio DNA Isolation kit (Prime Prep) according to the manufacturer's protocol. The $C d x-2$ polymorphism (rs11568820) was amplified with PCR using primers 5'-CAgCATgCCTgTCCT CAgC-3' and 5'-CCAgTACTgCCAgCTCCC-3' based on the report of Deng et al. ${ }^{(29)}$ and resulted in a $135 \mathrm{bp}$ product. PCR was performed for thirty cycles and at $68^{\circ} \mathrm{C}$ annealing temperature. DNA was digested with $C d x-2$ enzyme (Fermentas; Thermo Scientific). DNA was digested with Bpu10I (Fermentas; Thermo Scientific), and the products were analysed by electrophoresis on a $1.5 \%$ agarose gel containing ethidium bromide and were visualised in a gel documentation system (UVIdoc; UVItec). Bpu10I digestion reveals genotypes denoted AA (135 bp), GA (135, 72 and 63 bp) or GG (72 and 63 bp).

\section{Statistical analysis}

Data were expressed as means and standard deviations. Normal distribution of data was checked using Kolmogrov-Smirnov. Genotype frequencies of $C d x$-2 were tested for Hardy-Weinberg equilibrium using the $\chi^{2}$ test. We used the Cochran-Armitage test for trend $\left(\chi^{2} \text { linear by linear association }\right)^{(30)}$. Differences in proportions were evaluated using $\chi^{2}$ between treatment groups. Independent sample $t$ tests (for normally distributed variables) or Mann-Whitney $U$ tests (for non-normally distributed variables) were used to test anthropometric and metabolic biomarkers between the PD and FD groups. Correlations between variables were evaluated using either Pearson's $r$ (for data with normal distribution) or Spearman's $r_{s}$ (for data with non-normal distribution) equations. Repeated-measures ANOVA was used to evaluate time $\times$ group interactions, with time and group as factors. In case of significant time-group interaction, between-group comparison of changes at week 12 was carried out using ANOVA followed by Tukey's post hoc analysis with polynomial contrast analysis for trend when indicated. When time effect was significant, the within-group comparison of values was performed by paired sample $t$ tests. All statistical analyses were carried out using the Statistical Package for Social Sciences (version 18; SPSS). A $P$ value $<0.05$ was considered significant.

\section{Results}

\section{Patients' characteristics}

A flow chart of subject enrollment is shown in Fig. 1. The subjects included twenty-nine women and thirty-one men aged $52 \cdot 6$ (SD 7.8) years. Mean age (PD: $51 \cdot 3$ (sD 7.7), FD: $54 \cdot 1$ (sD 8.0) years), duration of disease (PD: $7 \cdot 2$ (SD 5.8), FD: 8.6 (SD 5.5) years) and sex ratio showed no significant difference between the groups (Table 1). Comparison of dietary data between the PD and FD groups showed no significant difference in the initial and final values of $\mathrm{Ca}$ intake (595.6 (SD 270.0) $v$. 530.8 (sD 216.4$) \mathrm{mg} / \mathrm{d} ; \quad P=0.140$ and 615.5 (SD 311.0) v. 640.4 (sD 315.1$) \mathrm{mg} ; P=0.660$, respectively). Nor was there any 


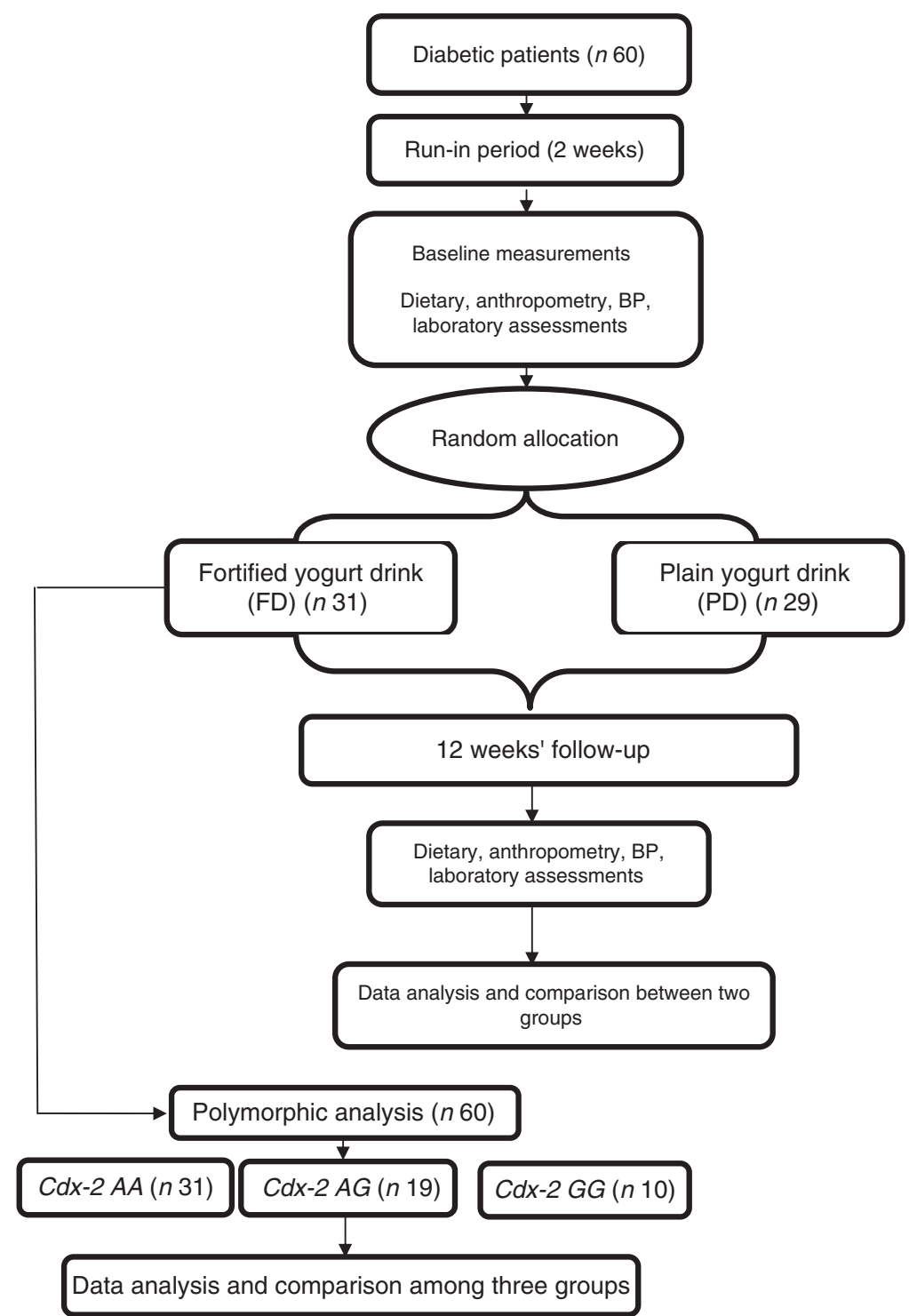

Fig. 1. Protocol of the study. BP, blood pressure; FD, fortified doogh; PD, plain doogh.

significant difference in the initial and final vitamin D intakes, excluding the amount consumed with the fortified dooghs in the FD group (0.39 (sD 0.34) v. 0.35 (sD 0.34) $\mu \mathrm{g} / \mathrm{d} ; P=0.607 ; 0.44$ (sD 0.55$) v .0 .40(\mathrm{sD} 0.48) \mu \mathrm{g} / \mathrm{d} ; P=0.670$, respectively).

In our study population, the observed genotype frequency distributions for $C d x-2$ were in Hardy-Weinberg equilibrium. Distribution of age, sex, duration of disease and sun exposure did not differ significantly among the genotypic groups (Table 1).

\section{Intervention study}

At baseline, vitamin D concentrations and other biomarkers were not significantly different between the two groups (Table 2). There were significant time effect between weeks 0 and 12 in serum 25(OH)D. Serum concentrations of $25(\mathrm{OH}) \mathrm{D}$ increased significantly in the FD group compared with baseline
$(P<0.001)$ and with PD $(+35.4 \mathrm{nmol} / 1$ in $\mathrm{FD} v .-4.8 \mathrm{nmol} / 1 \mathrm{in}$ PD; $P<0.001$ ) (Table 2). Accordingly, vitamin D status in FD, as compared with $\mathrm{PD}$, improved significantly after 12 weeks' intervention (Table 3). There were also significant time effects between weeks 0 and 12 for HbA1c, FM\% and VAT. Although in the FD group, HbA1c $(P<0.001)$, FM\% $(P<0.001)$ and VAT $(P<0.001)$ all decreased significantly after 12 weeks, in the PD group these variables tended to increase except for HbA1c that slightly but significantly decreased $(P=0 \cdot 03)$. There were also significant time $\times$ treatment interaction for $25(\mathrm{OH}) \mathrm{D}$, QUICKI, WC, waist:hip ratio (WHR), FM\%, VAT and TF\%. Analysis of changes within groups revealed a significant decrease in WC $(P=0.02)$, WHR $(P=0.05)$, FM\% $(P<0.008)$, VAT $(P<0.001)$ and $\mathrm{TF} \%(P=0.003)$ in the FD group compared with the PD group, whereas $25(\mathrm{OH}) \mathrm{D}$ and QUICKI significantly increased in the FD group compared with the PD group $(P<0 \cdot 001$ for both) (Table 2). Weight, BMI and FSG did not change significantly 
Table 1. Some selected individual characteristics of the subjects enrolled in the randomised clinical trial (RCT) study and Cdx-2 (rs11568820) genotypic groups for the nutrigenetic study (Mean values and standard deviations; percentages)

\begin{tabular}{|c|c|c|c|c|c|c|c|c|c|c|c|c|}
\hline \multirow[b]{3}{*}{ Variables } & \multicolumn{4}{|c|}{ Treatment groups ( $n 60)$} & \multirow[b]{3}{*}{$P$} & \multicolumn{6}{|c|}{$C d x-2$ genotypic groups $(n 60)$} & \multirow[b]{3}{*}{$P$} \\
\hline & \multicolumn{2}{|c|}{$\mathrm{PD}(n 29)$} & \multicolumn{2}{|c|}{$\mathrm{FD}(n 31)$} & & \multicolumn{2}{|c|}{$\mathrm{AA}(n 31)$} & \multicolumn{2}{|c|}{$\mathrm{AG}(n 19)$} & \multicolumn{2}{|c|}{$\mathrm{GG}(n 10)$} & \\
\hline & Mean & SD & Mean & SD & & Mean & SD & Mean & SD & Mean & SD & \\
\hline Age (years) & $51 \cdot 3$ & $7 \cdot 7$ & $54 \cdot 1$ & $8 \cdot 0$ & 0.16 & $52 \cdot 4$ & $7 \cdot 8$ & $52 \cdot 6$ & $7 \cdot 1$ & $56 \cdot 9$ & 8.9 & 0.14 \\
\hline Sex (male/female) & \multicolumn{2}{|c|}{$14 / 15$} & \multicolumn{2}{|c|}{$17 / 14$} & 0.61 & \multicolumn{2}{|c|}{$16 / 15$} & \multicolumn{2}{|c|}{$13 / 6$} & \multicolumn{2}{|c|}{$1 / 9$} & 0.01 \\
\hline Diabetes duration (years) & 7.2 & $5 \cdot 8$ & 8.6 & 5.5 & 0.34 & $7 \cdot 0$ & $5 \cdot 7$ & 8.9 & $7 \cdot 7$ & 8.0 & $5 \cdot 2$ & 0.58 \\
\hline Physical activity (\%)* & \multicolumn{2}{|c|}{45.5} & \multicolumn{2}{|c|}{37.5} & 0.53 & \multicolumn{2}{|c|}{46.5} & \multicolumn{2}{|c|}{38.4} & \multicolumn{2}{|c|}{$15 \cdot 2$} & 0.69 \\
\hline Sun exposure $(\mathrm{min} / \mathrm{d})$ & 59.0 & $66 \cdot 0$ & 67.6 & 38.3 & 0.60 & $57 \cdot 0$ & $64 \cdot 0$ & 71.4 & 40 & $45 \cdot 0$ & $15 \cdot 0$ & 0.65 \\
\hline
\end{tabular}

$\mathrm{PD}$, plain doogh; FD, vitamin D-fortified doogh.

* Very low physical activity.

Table 2. Comparison of the initial and final values of the variables under study in the randomised clinical trial (RCT) (Mean values and standard deviations)

\begin{tabular}{|c|c|c|c|c|c|c|c|c|c|c|c|c|c|c|c|}
\hline \multirow[b]{3}{*}{ Variables } & \multicolumn{6}{|c|}{ Plain doogh (n 29) } & \multicolumn{6}{|c|}{ Fortified doogh ( $n$ 31) } & \multirow{3}{*}{$\frac{\text { Time }}{P_{1}}$} & \multirow{3}{*}{$\frac{\text { Group }}{P_{2}}$} & \multirow{3}{*}{$\frac{\text { Time } \times \text { group }}{P_{3}}$} \\
\hline & \multicolumn{2}{|c|}{ Before } & \multicolumn{2}{|c|}{ After } & \multicolumn{2}{|c|}{ Change } & \multicolumn{2}{|c|}{ Before } & \multicolumn{2}{|c|}{ After } & \multicolumn{2}{|c|}{ Change } & & & \\
\hline & Mean & SD & Mean & SD & Mean & SD & Mean & SD & Mean & SD & Mean & SD & & & \\
\hline 25(OH)D (nmol/l) & $41 \cdot 1$ & 20.5 & $36 \cdot 2$ & $23 \cdot 6$ & $-4 \cdot 8$ & $16 \cdot 6$ & 41.6 & $15 \cdot 9$ & $77 \cdot 1$ & 19.7 & 35.4 & $18 \cdot 3$ & $<0.001$ & $<0.001$ & $<0.001$ \\
\hline $\mathrm{FSG}(\mathrm{mmol} / \mathrm{l})$ & 8.87 & $2 \cdot 9$ & $9 \cdot 3$ & 2.9 & 0.44 & $2 \cdot 7$ & $9 \cdot 3$ & $2 \cdot 4$ & 8.5 & $2 \cdot 4$ & -0.77 & 2.76 & 0.63 & 0.70 & 0.08 \\
\hline HbA1c (propotional) & 8.9 & 1.7 & 8.3 & 1.6 & -0.71 & $1 \cdot 7$ & 8.9 & 2.4 & 7.4 & 1.6 & -1.5 & $2 \cdot 0$ & $<0.001$ & 0.24 & 0.12 \\
\hline QUICKI" & 0.28 & 0.2 & 0.28 & 0.02 & -0.009 & 0.02 & 0.28 & 0.02 & 0.29 & 0.02 & 0.02 & 0.02 & 0.67 & 0.70 & $<0.001$ \\
\hline Weight $(\mathrm{kg})^{\star}$ & 78.8 & $13 \cdot 2$ & $79 \cdot 7$ & $13 \cdot 8$ & 0.86 & $2 \cdot 6$ & $73 \cdot 7$ & 13.8 & 73.5 & 11.5 & -0.2 & $2 \cdot 7$ & 0.32 & 0.13 & 0.16 \\
\hline WC $(\mathrm{cm})$ & $101 \cdot 1$ & 9.8 & $102 \cdot 2$ & $10 \cdot 8$ & 1.6 & 4.4 & $96 \cdot 8$ & 11.4 & 95.8 & 8.9 & $-1 \cdot 3$ & $5 \cdot 0$ & 0.80 & 0.046 & 0.028 \\
\hline WHR & 0.94 & 0.05 & 0.95 & 0.05 & 0.02 & 0.04 & 0.93 & 0.05 & 0.92 & 0.05 & -0.05 & 0.04 & 0.27 & 0.07 & 0.051 \\
\hline FM\%* & 38.9 & 9.6 & $40 \cdot 3$ & 9.4 & 0.60 & $3 \cdot 3$ & $35 \cdot 2$ & $10 \cdot 6$ & 33.3 & 9.6 & -1.9 & $2 \cdot 0$ & $<0.001$ & 0.037 & $<0.008$ \\
\hline VAT (AU) & 14.4 & 3.8 & $15 \cdot 0$ & 3.4 & 0.37 & 1.8 & $13 \cdot 3$ & 4.3 & $12 \cdot 0$ & 4.6 & -0.80 & 0.96 & 0.009 & 0.85 & $<0.001$ \\
\hline Truncal fat (\%) & 38.8 & 8.6 & 39.7 & 7.8 & $0 \cdot 13$ & 0.87 & $35 \cdot 9$ & 9.6 & 34.7 & 9.5 & $-1 \cdot 1$ & 2.0 & 0.11 & 0.27 & 0.003 \\
\hline
\end{tabular}

$P_{1}$, probability level by repeated-measures ANOVA for difference in time course; $P_{2}$, probability level by repeated-measures ANOVA for difference between types of yogurt drink; $P_{3}$, probability level by repeated-measures ANOVA for interaction between time course and type of yogurt drink; 25(OH)D, 25-hydroxyvitamin D; FSG, fasting serum glucose; HbA1c, glycated Hb; QUICKI, Quantitative Insulin Check Index; WC, waist circumference, WHR, waisthip ratio; FM, fat mass, VAT, visceral adipose tissue.

* Sample size $=$ thirty subjects in the fortified doogh group. 
Table 3. Comparison of the vitamin D status between plain doogh (PD) and vitamin D-fortified doogh (FD) groups (Numbers and percentages)

\begin{tabular}{|c|c|c|c|c|c|c|c|c|c|c|c|c|}
\hline & \multicolumn{4}{|c|}{ Deficiency $^{*}$} & \multicolumn{4}{|c|}{ Insufficiency* ${ }^{*}$} & \multicolumn{4}{|c|}{ Sufficiency ${ }^{*}$} \\
\hline & \multicolumn{2}{|c|}{ Before } & \multicolumn{2}{|c|}{ After } & \multicolumn{2}{|c|}{ Before } & \multicolumn{2}{|c|}{ After } & \multicolumn{2}{|c|}{ Before } & \multicolumn{2}{|c|}{ After } \\
\hline & $n$ & $\%$ & $n$ & $\%$ & $n$ & $\%$ & $n$ & $\%$ & $n$ & $\%$ & $n$ & $\%$ \\
\hline PD & 6 & $20 \cdot 7$ & 12 & 41.2 & 16 & $55 \cdot 2$ & 12 & $41 \cdot 2$ & 7 & $24 \cdot 1$ & 5 & $17 \cdot 2$ \\
\hline FD & 6 & 19.4 & 0 & 0 & 17 & 54.8 & 4 & $12 \cdot 9$ & 8 & $25 \cdot 8$ & 27 & $87 \cdot 1$ \\
\hline Total & 12 & 20 & 12 & $22 \cdot 2$ & 33 & 55.0 & 16 & $26 \cdot 7$ & 15 & $15 \cdot 0$ & 32 & $51 \cdot 1$ \\
\hline
\end{tabular}

* Deficiency $<27.5 \mathrm{nmol} / / ; 27.5 \mathrm{nmol} / \mathrm{I} \leq$ insufficiency $<50 \mathrm{nmol} / /$ and sufficiency $\geq 50 \mathrm{nmol} / \mathrm{l}$.

either within or between groups after 12 weeks (Table 2). We found a significant negative correlation between changes in serum 25(OH)D and changes of WC $(r-0 \cdot 29 ; P=0 \cdot 35)$, FM\% $(r$ $-0 \cdot 45 ; P=0 \cdot 001), \mathrm{TF} \%(r-0.32 ; P=0.015)$ and VAT $(r-0.44$; $P=0 \cdot 001)$.

\section{Nutrigenetic study}

There was no significant difference in any of the initial variables among the genotypic groups. However, a significant time effect was observed between weeks 0 and 12 for serum 25(OH)D. Although in the AA group, serum $25(\mathrm{OH}) \mathrm{D}$ increased significantly after 12 weeks $(P<0.001)$, in the other groups (AG and GG), no significant change was observed $(P=0 \cdot 15$ and $0 \cdot 63$, respectively) (Table 4). Reanalysis of data among $C d x-2$ variants revealed no significant trend for distribution of vitamin D deficiency through $C d x-2$ genotypes $\left(\chi^{2}=0.03 ; P_{\text {trend }}=0.86\right)$ at baseline. However, after intervention, trend test was significant $\left(\chi^{2}=29 \cdot 1 ; P_{\text {trend }}<0.001\right)$ showing $>60 \%$ of subjects in the GG genotype, and $98 \%$ of subjects in AG genotype were deficient after 12 weeks' intervention (Table 5). There were also significant time effects between weeks 0 and 12 for HbA1c and FM\%. Although in the AA group, both HbA1c $(P<0.001)$ and FM\% $(P=0.01)$ decreased significantly after 12 weeks, in AG ( $P=0.18$ for HbA1c and $P=0.09$ for FM\%) and GG ( $P=0.06$ for HbA1c and $P=0.56$ for FM\%) groups, these variables did not change (Table 4). There were significant time $\times$ treatment interaction for $25(\mathrm{OH}) \mathrm{D}$, QUICKI, WC, $\mathrm{FM} \%$, VAT and $\mathrm{TF} \%$ among $C d x-2$ genotypes (Table 4). Post hoc Tukey's test revealed that the AA group had significantly higher $25(\mathrm{OH}) \mathrm{D}$ compared with that of AG $(P<0.001)$ and GG $(P=0.006)$ after 12 weeks. Circulating $25(\mathrm{OH}) \mathrm{D}$ was unexpectedly raised only in the AA group compared with the other groups $(P<0 \cdot 001)$. This difference was accompanied by a significant difference for other obesity markers such as WC, FM\% and TF\%, which significantly decreased in AA genotype $(P=0.004,<0.001$ and $<0 \cdot 001$, respectively). When changes of the variables were compared using ANOVA followed by Tukey's post hoc test, a significant difference in 25(OH)D was observed between AA and AG $(P<0.001)$ and AA and GG $(P<0.001)$, but the differences between AG and GG $(P=0.77)$ were not statistically significant. As for FM\%, AA differed significantly from both AG $(P<0.001)$ and GG $(P=0.05)$, but there was no significant difference between AG and GG $(P=0.60)$. In addition, TF\% showed a significant difference between AA and AG
( $P=0.008)$, but there was no significant difference between AA and GG $(P=0.24)$ or between AG and GG $(P=0.69)$. In addition, we observed significant difference in VAT among $C d x-2$ genotypes in which the AA group showed significant decrease in VAT compared with AG $(P=0 \cdot 001)$. Again here, AG and GG as well as AA and GG did not differ significantly $(P=0.11$ and $0 \cdot 61$ ). Moreover, the AA group had significantly higher difference in QUICKI compared with AG $(P=0.02)$ and GG $(P=0.001)$. However, there was no significant difference between AG and GG in QUICKI changes $(P=0 \cdot 35)$.

\section{Discussion}

This study showed that an intake of $25 \mu \mathrm{g} / \mathrm{d}$ vitamin D through FD has beneficial effects on the central obesity indicators, including TF and visceral adiposity in subjects with T2D, and these effects were more pronounced in those patients who were carrier of AA genotype of VDR- $C d x$-2 polymorphism.

Emerging data from observational studies showed an inverse association between $25(\mathrm{OH}) \mathrm{D}$ status and adiposity. More specifically, two published studies have shown an inverse association between vitamin D and visceral adiposity ${ }^{(31)}$ and between baseline BMI and subcutaneous adipose tissue $(\mathrm{SAT})^{(8)}$ in Hispanic and African-Americans, but 25(OH)D was not associated with 5 -year change in adiposity ${ }^{(8)}$.

The relationship between vitamin D status and adiposity has been under the effect of racial differences. For instance, the inverse association between body fat (assessed by bioelectrical impedance) and serum $25(\mathrm{OH}) \mathrm{D}$ varied by race and was stronger in whites compared with blacks ${ }^{(32)}$. Moreover, the association of FM with vitamin D was consistent irrespective of the body fat location, and the correlation of vitamin D deficiency with body fat parameters was stronger than with BMI or WC. In other words, BMI and WC were not independent factors related to the vitamin D status ${ }^{(33)}$.

Moreover, the prevalence of poor vitamin D status $(25(\mathrm{OH})$ $\mathrm{D}<50 \mathrm{nmol} / \mathrm{l}$ ) was 3-fold higher in subjects with high SAT and high VAT than in those with low SAT and low VAT ${ }^{(34)}$. CaronJobin et al. have found that both high dietary vitamin D intakes and serum 25(OH)D were significantly associated with lower VAT area. Additionally, serum concentration of $25(\mathrm{OH}) \mathrm{D}$ was also closely associated with overall adiposity measured using BMI or total body $\mathrm{FM}^{(35)}$.

Our finding of decrease in FM and VAT mediated by vitamin D supports earlier randomised trials in which after 16 weeks 
significant reduction was observed in VAT, following daily intake of Ca-vitamin D-fortified orange juice $(350 \mathrm{mg}$ and $100 \mathrm{IU} / \mathrm{d}$ ). Similar to our findings, they did not observe any significant effect on BMI and weight ${ }^{(20)}$. Nevertheless, in a longitudinal study, Ca plus vitamin D had a small effect in the prevention of weight gain over 3 years ${ }^{(13)}$. Similarly, two clinical trials showed no significant changes in body weight, percentage FM or waist:hip ratios after high vitamin D supplementation levels in overweight and/or obese subjects ${ }^{(36,37)}$.

Our findings are in accord with some other studies that reported most of vitamin D-induced adiposity reduction is related to VAT changes ${ }^{(35)}$. The relationship among adipocyte size, dietary intakes of vitamin D and $\mathrm{Ca}$ and 25(OH)D concentrations has been reported only in the omental depot ${ }^{(35)}$. It is suggested that range of BMI could be an important predictor of reduction rate and site of reduction in adipose tissue ${ }^{(35)}$. In our population, mean of BMI was in overweight and obesity range (88.3\% of our patients were obese and the remaining were overweight). The hypothesis is that, in this range of BMI, variance of SAT is lower than that of VAT, which may lead to more efficacy of supplementation on VAT measures ${ }^{(35)}$.

Mechanistically, 1,25(OH)2D induces intestinal Ca absorption, controls bone remodelling, suppresses parathyroid hormone synthesis and favours renal Ca re-absorption ${ }^{(38)}$. All of aforementioned mechanisms then modulate the intracellular $\mathrm{Ca}$, which involves in alteration of lipolysis or lipogenesis ${ }^{(38)}$. Moreover, it was suggested that low dietary intakes of vitamin D can induce production of $1,25(\mathrm{OH}) 2 \mathrm{D}$, which then could induce cortisol production by activating $11 \beta$-hydroxysteroid dehydrogenase. The increase in the activity of this enzyme in humans can induce accumulation of FM in visceral area ${ }^{(39,40)}$. Whereas vitamin $\mathrm{D}$ and its metabolites could be sequestered in fat tissue $^{(7)}$, following vitamin D supplementation, the activity of the enzyme might reduce, which later can induce lipolysis.

We found the differences of genotype frequencies of VDR$C d x-2$ between patients from Iranian and the other countries, including European ${ }^{(41)}$, Chinese $^{(42)}$ and South Asian ${ }^{(43)}$, previously reported (Table 6). For example, while the relative genotype frequencies of $C d x-2$ polymorphism in Iranian patients were AA 51.6, AG 31.7 and GG $16.7 \%$, the genotype frequencies in South Asians were AA 18, AG $55 \cdot 2$ and GG $26 \cdot 8 \%{ }^{(43)}$, whereas the frequencies determined on European were AA 04.0, AG $32 \cdot 0^{(41)}$ and GG $64 \cdot 0 \%$. Moreover, a study in Chinese men ${ }^{(42)}$ showed that the genotype distributions for $C d x-2$ was AA 26.0, AG 44.4 and GG $29.6 \%$. It is possible that racial differences are involved in environmental or genetic factors.

We observed that $C d x-2$ polymorphism significantly modified the efficacy of $25 \mu \mathrm{g} / \mathrm{d}$ vitamin D supplementation for increasing $25(\mathrm{OH}) \mathrm{D}$ and changing obesity indices. The circulating 25(OH)D was unexpectedly raised only in AA group compared with the other genotypic groups. This difference was accompanied by a significant difference of other obesity indices such as WC, FM\% and TF\% that significantly decreased in AA genotype.

It is noteworthy that the GG group had higher body weight and $\mathrm{FM} \%$. In interventional studies, actually the baseline levels of variables are critical determinant of response to the intervention. However, we did not observe any significant changes 
Table 5. Vitamin D status among the $C d x-2$ genotypic subgroups before and after the intervention (Numbers and percentages)

\begin{tabular}{|c|c|c|c|c|c|c|c|c|c|c|c|c|c|c|c|c|}
\hline & \multicolumn{4}{|c|}{$\mathrm{AA}\left(n_{1} 31\right)$} & \multicolumn{4}{|c|}{$\mathrm{AG}\left(n_{2} 19\right)$} & \multicolumn{4}{|c|}{$\mathrm{GG}\left(n_{3} 10\right)$} & \multicolumn{4}{|c|}{ Total } \\
\hline & \multicolumn{2}{|c|}{ Before } & \multicolumn{2}{|c|}{ After } & \multicolumn{2}{|c|}{ Before } & \multicolumn{2}{|c|}{ After } & \multicolumn{2}{|c|}{ Before } & \multicolumn{2}{|c|}{ After } & \multicolumn{2}{|c|}{ Before } & \multicolumn{2}{|c|}{ After } \\
\hline & $n$ & $\%$ & $n$ & $\%$ & $n$ & $\%$ & $n$ & $\%$ & $n$ & $\%$ & $n$ & $\%$ & $n$ & $\%$ & $n$ & $\%$ \\
\hline Deficiency & 6 & $19 \cdot 4$ & 0 & 0 & 4 & $68 \cdot 4$ & 10 & 52.6 & 2 & $20 \cdot 0$ & 3 & $30 \cdot 0$ & 12 & $20 \cdot 0$ & 13 & $21 \cdot 7$ \\
\hline Insufficiency & 17 & $54 \cdot 8$ & 6 & $19 \cdot 3$ & 13 & $68 \cdot 4$ & 8 & $42 \cdot 1$ & 3 & 30.0 & 3 & 33.8 & 33 & $55 \cdot 0$ & 17 & $28 \cdot 3$ \\
\hline Sufficiency & 8 & $25 \cdot 8$ & 25 & 80.6 & 2 & 10.5 & 1 & $5 \cdot 3$ & 5 & 50.0 & 4 & 44.4 & 15 & $25 \cdot 0$ & 30 & 50.0 \\
\hline
\end{tabular}

Vitamin $D$ status definition based on serum 25-hydroxyvitamin $D$ as deficiency $<27.5 \mathrm{nmol} / / 27.5 \mathrm{nmol} / / \leq$ insufficiency $<50 \mathrm{nmol} / /$ and sufficiency $\geq 50 \mathrm{nmol} / \mathrm{l}$.

Table 6. The differences of genotype frequencies of $C d x-2$ VDR gene between patients from Iranian and the other countries (Numbers and percentages)

\begin{tabular}{|c|c|c|c|c|c|c|c|c|c|}
\hline \multirow[b]{2}{*}{$C D X-2$} & \multicolumn{2}{|c|}{ AA } & \multicolumn{2}{|c|}{$A G$} & \multicolumn{2}{|c|}{ GG } & \multicolumn{2}{|c|}{ Total } & \multirow[b]{2}{*}{ References } \\
\hline & $n$ & $\%$ & $n$ & $\%$ & $n$ & $\%$ & $n$ & $\%$ & \\
\hline Iranian & 31 & $51 \cdot 6$ & 19 & 31.7 & & $51 \cdot 6$ & 60 & 100 & This study \\
\hline South Asian & 43 & 18 & 132 & $55 \cdot 2$ & 64 & $26 \cdot 8$ & 239 & 100 & (43) \\
\hline European & 23 & 4 & 176 & 32 & 346 & 64 & 545 & 100 & (41) \\
\hline Chinese & 108 & 26 & 184 & 44.4 & 123 & 29.6 & 415 & 100 & (42) \\
\hline
\end{tabular}

in FM and body weight in this group. It is well accepted that the A allele is more 'active' than the $\mathrm{G}$ allele by binding the $C d x-2$ transcription factor more strongly and by having more transcriptional activity. Then, the A allele seems to cause increased VDR expression in the intestine leading to an increased transcription of Ca transport proteins such as calbindin that finally enhance the intestinal absorption of $\mathrm{Ca}$ and, thereby, result in increased $\mathrm{BMD}^{(44)}$. $C d x-2$ polymorphism has previously been associated with clinical outcomes and $\mathrm{Ca}$ absorption. Our results support previous findings of observational and molecular studies $^{(19,45)}$. Recently, Ochs-Balcom et al. ${ }^{(19)}$ observed a positive association of $C d x-2$ with WC and abdominal height, and a borderline significant association between $C d x-2$ and BMI. Later on, in a longitudinal study it was shown that $C d x-2$ did not increase the odds of central obesity ${ }^{(46)}$. In another study, the $C d x-2$ SNP was associated with BMI and FM in Chinese men ${ }^{(42)}$. Arai et al. ${ }^{(45)}$, have shown that this polymorphism (an A-G transition in the intestine-specific binding site of transcription factor $C d x-2$ in the $5^{\prime}$ promoter region of VDR) results in a $30 \%$ reduction in transcriptional activity of the promoter, decreases intestinal VDR expression and affects Ca absorption in the intestine.

Another finding is that in the GG genotype group the baseline level of $25(\mathrm{OH}) \mathrm{D}$ was higher than that of the other genotype groups, without any significant changes after vitamin D intake for 12 weeks. However, this is an unusual finding without any decisive explanation. The only explanation is that mutation at this site $(C d x-2)$ may lead to lower production of mRNA and then lower production of active VDR protein ${ }^{(47)}$.

Limitations of our study should be acknowledged. Extension of the changes observed after 12 weeks' intervention to longer periods of time and, above all, their possible protective effect against long-term diabetes complications requires welldesigned longitudinal controlled studies. Additionally, the sample size was relatively small, and the subjects recruited were mainly middle-aged and elderly, limiting the ability to generalise these findings to the more heterogeneous population. Finally, the majority of BIA equations underestimated percent body fat as body fat increased ${ }^{(48)}$.

In conclusion, the key findings of the present study point to an efficacy of intake of $25 \mu \mathrm{g} / \mathrm{d}$ vitamin D through FD on the central obesity markers, including TF and visceral adiposity in the subjects with T2D. To our knowledge, this is the first study to examine the interactive effects of VDR- $C d x-2$ polymorphism and vitamin $\mathrm{D}$ intake on central obesity indices of diabetes host response. According to the high prevalence of vitamin D deficiency in Iran and a rather high proportion of non-responders in $C d x-2$ genotypes (AG and GG) to vitamin D intake, stakeholders may need a better policy for the proportion of the community in whom up to $25 \mu \mathrm{g} / \mathrm{d}$ vitamin $\mathrm{D}$ may not be effective enough to improve insulin resistance and related morbidities. Further, nutritional support may be 'tailored' individually according to their genotype. However, further research is needed to replicate those findings in different populations, including populations of other racial and ethnic groups, in order to confirm the biological significance of $C d x-2$ polymorphism in relation to central obesity phenotype.

\section{Acknowledgements}

The authors thank the Iranian Diabetic Society and Gabric Diabetic Society for their collaborations. The authors sincerely appreciate all the subjects for their participation in this study.

This study was funded by NNFTRI (grant no. 035360), TUMS (grant no. 10533) and Iran National Science Foundation (grant no. 8800420), in order of their financial contributions.

T. R. N. designed and supervised the study, was involved in laboratory analyses and wrote the finalised manuscript. A. D. 
and S. S.-B. both helped intellectually in finalising the study design. S. S.-B. performed most of the laboratory analyses, wrote the preliminary manuscript and was actively involved in the field work

There are no conflicts of interest to declare.

\section{References}

1. Kelishadi R, Alikhani S, Delavari A, et al. (2008) Obesity and associated lifestyle behaviours in Iran: findings from the first national non-communicable disease risk factor surveillance survey. Public Health Nutr 11, 246-251.

2. Salekzamani S, Neyestani TR, Alavi-Majd H, et al. (2011) Is vitamin $\mathrm{D}$ status a determining factor for metabolic syndrome? A case-control study. Diabetes Metab Syndr Obes 4, 205-212.

3. Hill JO \& Peters JC (1998) Environmental contributions to the obesity epidemic. Science 280, 1371-1374.

4. Dennis KE (2007) Postmenopausal women and the health consequences of obesity. J Obstet Gynecol Neonat Nurs 36, 511-519.

5. Arunabh S, Pollack S, Yeh J, et al. (2003) Body fat content and 25-hydroxyvitamin D levels in healthy women. J Clin Endocrinol Metab 88, 157-161.

6. Kamycheva E, Joakimsen RM \& Jorde R (2003) Intakes of calcium and vitamin $\mathrm{D}$ predict body mass index in the population of Northern Norway. J Nutr 133, 102-106.

7. Wortsman J, Matsuoka LY, Chen TC, et al. (2000) Decreased bioavailability of vitamin D in obesity. Am J Clin Nutr 72, 690-693.

8. Young KA, Engelman CD, Langefeld CD, et al. (2009) Association of plasma vitamin $\mathrm{D}$ levels with adiposity in Hispanic and African Americans. J Clin Endocrinol Metab 94, 3306-3313.

9. Parikh SJ, Edelman M, Uwaifo GI, et al. (2004) The relationship between obesity and serum 1, 25-dihydroxy vitamin D concentrations in healthy adults. J Clin Endocrinol Metab 89, 1196-1199.

10. Hajer GR, van Haeften TW \& Visseren FL (2008) Adipose tissue dysfunction in obesity, diabetes, and vascular diseases. Eur Heart J 29, 2959-2971.

11. Zemel MB \& Miller SL (2004) Dietary calcium and dairy modulation of adiposity and obesity risk. Nutr Rev $\mathbf{6 2}$, 125-131.

12. Soares M, Ping-Delfos WCS \& Ghanbari M (2011) Calcium and vitamin $D$ for obesity: a review of randomized controlled trials. Eur J Clin Nutr 65, 994-1004.

13. Caan B, Neuhouser M, Aragaki A, et al. (2007) Calcium plus vitamin D supplementation and the risk of postmenopausal weight gain. Arch Intern Med 167, 893-902.

14. Wood RJ (2008) Vitamin D and adipogenesis: new molecular insights. Nutr Rev 66, 40-46.

15. Kong J \& Li YC (2006) Molecular mechanism of 1 , 25-dihydroxyvitamin D3 inhibition of adipogenesis in 3T3-L1 cells. Am J Physiol Endocrinol Metab 290, E916-E924.

16. Burton GR, Guan Y, Nagarajan R, et al. (2002) Microarray analysis of gene expression during early adipocyte differentiation. Gene 293, 21-31.

17. Yamamoto H, Miyamoto KI, Li B, et al. (1999) The caudalrelated homeodomain protein $\mathrm{Cdx}-2$ regulates vitamin $\mathrm{D}$ receptor gene expression in the small intestine. J Bone Miner Res 14, 240-247.

18. Zemel MB, Shi H, Greer B, et al. (2000) Regulation of adiposity by dietary calcium. FASEB J 14, 1132-1138.
19. Ochs-Balcom HM, Chennamaneni R, Millen AE, et al. (2011) Vitamin D receptor gene polymorphisms are associated with adiposity phenotypes. Am J Clin Nutr 93, 5-10.

20. Rosenblum JL, Castro VM, Moore CE, et al. (2012) Calcium and vitamin D supplementation is associated with decreased abdominal visceral adipose tissue in overweight and obese adults. Am J Clin Nutr 95, 101-108.

21. Neyestani TR, Djazayery A, Shab-Bidar S, et al. (2013) Vitamin D receptor Fok-I Polymorphism modulates diabetic host response to vitamin $\mathrm{D}$ intake need for a nutrigenetic approach. Diabetes Care 36, 550-556.

22. Shab-Bidar S, Neyestani TR \& Djazayery A (2011) Efficacy of vitamin D3-fortified-yogurt drink on anthropometric, metabolic, inflammatory and oxidative stress biomarkers according to vitamin $\mathrm{D}$ receptor gene polymorphisms in type 2 diabetic patients: a study protocol for a randomized controlled clinical trial. BMC Endocr Disord 11, 12.

23. Prevention I \& TYPE DO (2011) Standards of medical care in diabetes-2011. Diabetes Care 34, S11-S61.

24. Shab-Bidar S, Neyestani TR, Djazayery A, et al. (2011) Regular consumption of vitamin D-fortified yogurt drink (Doogh) improved endothelial biomarkers in subjects with type 2 diabetes: a randomized double-blind clinical trial. BMC Med 9, 125 .

25. Neyestani TR, Gharavi A \& Kalayi A (2007) Determination of serum 25-hydroxy cholecalciferol using high-performance liquid chromatography: a reliable tool for assessment of vitamin D status. Int J Vitam Nutr Res 77, 341-346.

26. Saintonge S, Bang H \& Gerber LM (2009) Implications of a new definition of vitamin D deficiency in a multiracial us adolescent population: the National Health and Nutrition Examination Survey III. Pediatrics 123, 797-803.

27. Ross AC, Manson JE, Abrams SA, et al. (2011) The 2011 report on dietary reference intakes for calcium and vitamin D from the Institute of Medicine: what clinicians need to know. J Clin Endocrinol Metab 96, 53-58.

28. Hrebicek J, Janout Vr, Malinčiková J, et al. (2002) Detection of insulin resistance by simple quantitative insulin sensitivity check index QUICKI for epidemiological assessment and prevention. J Clin Endocrinol Metab 87, 144-147.

29. Deng HW, Shen H, Xu FH, et al. (2002) Tests of linkage and/ or association of genes for vitamin D receptor, osteocalcin, and parathyroid hormone with bone mineral density. $J$ Bone Miner Res 17, 678-686.

30. Yong Zou G \& Donner A (2006) The merits of testing HardyWeinberg equilibrium in the analysis of unmatched case-control data: a cautionary note. Ann Hum Genet 70, 923-933.

31. Freedman BI, Wagenknecht LE, Hairston KG, et al. (2010) Vitamin D, adiposity, and calcified atherosclerotic plaque in African-Americans. J Clin Endocrinol Metab 95, 1076-1083.

32. Looker AC (2005) Body fat and vitamin D status in black versus white women. J Clin Endocrinol Metab 90, 635-640.

33. Rajakumar K, de Las Heras J, Chen TC, et al. (2011) Vitamin D status, adiposity, and lipids in black American and Caucasian children. J Clin Endocrinol Metab 96, 1560-1567.

34. Cheng S, Massaro JM, Fox CS, et al. (2010) Adiposity, cardiometabolic risk, and vitamin D status: the Framingham Heart Study. Diabetes 59, 242-248.

35. Caron-Jobin M, Morisset AS, Tremblay A, et al. (2011) Elevated serum $25(\mathrm{OH}) \mathrm{D}$ concentrations, vitamin $\mathrm{D}$, and calcium intakes are associated with reduced adipocyte size in women. Obesity 19, 1335-1341.

36. Sneve M, Figenschau Y \& Jorde R (2008) Supplementation with cholecalciferol does not result in weight reduction in overweight and obese subjects. Eur J Endocrinol 159, 675-684. 
37. Zittermann A, Frisch S, Berthold HK, et al. (2009) Vitamin D supplementation enhances the beneficial effects of weight loss on cardiovascular disease risk markers. Am J Clin Nutr 89, 1321-1327.

38. Zemel MB (2003) Mechanisms of dairy modulation of adiposity. J Nutr 133, 252S-256S

39. Veilleux A, Rhéaume C, Daris M, et al. (2009) Omental adipose tissue type 1 11ß-hydroxysteroid dehydrogenase oxoreductase activity, body fat distribution, and metabolic alterations in women. J Clin Endocrinol Metab 94, 3550-3557.

40. Veilleux A, Laberge PY, Morency J, et al. (2010) Expression of genes related to glucocorticoid action in human subcutaneous and omental adipose tissue. J Steroid Biochem Mol Biol 122, 28-34.

41. Wehr E, Trummer O, Giuliani A, et al. (2011) Vitamin D-associated polymorphisms are related to insulin resistance and vitamin D deficiency in polycystic ovary syndrome. Eur J Endocrinol 164, 741-749.

42. Gu J-m, Xiao W-j, He J-w, et al. (2009) Association between VDR and ESR1 gene polymorphisms with bone and obesity phenotypes in Chinese male nuclear families. Acta Pharmacol Sin 30, 1634-1642.
43. Jain R, von Hurst PR, Stonehouse W, et al. (2012) Association of vitamin D receptor gene polymorphisms with insulin resistance and response to vitamin D. Metabolism 61, 293-301.

44. Arai H, Miyamoto KI, Yoshida M, et al. (2001) The polymorphism in the caudal-related homeodomain protein $\mathrm{Cdx}-2$ binding element in the human vitamin $\mathrm{D}$ receptor gene. J Bone Miner Res 16, 1256-1264.

45. Arai H, Miyamoto KI, Taketani Y, et al. (1997) A vitamin D receptor gene polymorphism in the translation initiation codon: effect on protein activity and relation to bone mineral density in Japanese women. J Bone Miner Res 12, 915-921.

46. Beydoun MA, Tanaka T, Beydoun HA, et al. (2013) Vitamin D receptor and megalin gene polymorphisms are associated with central adiposity status and changes among US adults. J Nutr Sci 2, e33.

47. Uitterlinden AG, Fang Y, van Meurs JB, et al. (2004) Genetics and biology of vitamin D receptor polymorphisms. Gene 338, 143-156.

48. Newton R, Alfonso A, White M, et al. (2005) Percent body fat measured by BIA and DEXA in obese, African-American adolescent girls. Int J Obes 29, 594-602. 